\title{
Neurologic manifestations of COVID-19
}

\section{Manifestaciones neurológicas por COVID-19}

\author{
Amado Jiménez-Ruiz, ${ }^{1 *}$ Miguel García-Grimshaw ${ }^{2}$ and José L. Ruiz-Sandovaß ${ }^{3}$ \\ ${ }^{1}$ Western University, Department of Neurology, Ontario, Canada; ${ }^{2}$ Instituto Nacional de Ciencias Médicas y Nutrición "Salvador Zubirán", Department \\ of Neurology, Mexico City, Mexico; ${ }^{3}$ Hospital Civil de Guadalajara "Fray Antonio Alcalde", Department of Neurology, Jalisco, Mexico
}

The COVID-19 pandemic, which started in China, has spread rapidly to affect the entire world in a matter of months. Main manifestations of the disease include a febrile syndrome accompanied by respiratory symptoms; however, cases of systemic involvement are increasingly being reported, including cardiac and central nervous system compromise. In the series by Ling M. et al., 214 patients with COVID-19 were studied; 78 (36.4\%) had neurologic manifestations, which were classified into four main groups: acute cerebrovascular disease, impaired consciousness, peripheral nervous system involvement and muscular manifestations. ${ }^{1}$ Another report published by $\mathrm{Li}$ et al. describes that, out of 221 patients with COVID-19, 13 developed acute cerebrovascular disease with cerebral infarction, venous thrombosis and intracerebral hemorrhage. ${ }^{2}$

Acute respiratory distress syndrome is the main cause of death in COVID-19 patients, which is explained by an intense pulmonary inflammatory reaction. ${ }^{3}$ There is evidence that the virus might be able to invade the central nervous system through the brain stem and affect the regulation of respiratory centers, thus contributing to refractory respiratory failure, as well as to the development of some manifestations such as hyposmia and dysgeusia. ${ }^{4}$

In Mexico, COVID-19 cases are increasingly being identified, and thus we must bear in mind infectious and non-infectious complications that affect the nervous system such as encephalitis, seizures, Guillain-Barré syndrome, disseminated encephalomyelitis and hemorrhagic leukoencephalitis, which are disorders that can occur during or after viral infections. A neurological symptom could be the first manifestation of COVID-19.

\section{Conflict of interests}

The authors declare that they have no conflicts of interest.

\section{Funding}

The authors declare that they did not receive any sponsoring to carry out this article.

\section{References}

1. Mao L, Wang M, Chen S, He Q, Chang J, Hong C, et al. Neurological manifestations of hospitalized patients with COVID-19 in Wuhan, China: a retrospective case series study. medRxiv. 2020 Feb 25. [Epub ahead of print].

2. Li Y, Wang M, Zhou Y, Chang J, Xian Y, Mao L, et al. Acute cerebrovascular disease following COVID-19: a single center, retrospective, observational study. Soc Sci Res Net; 2020 Mar 13. [Epub ahead of print]

3. Tian S, Hu W, Niu L, Liu H, Xu H, Xiao SY. Pulmonary pathology of early-phase 2019 novel coronavirus (COVID-19) pneumonia in two patients with lung cancer. J Thorac Oncol. 2020 Feb 27. [Epub ahead of print].

4. Li YC, Bai WZ, Hashikawa T. The neuroinvasive potential of SARS-CoV2 may play a role in the respiratory failure of COVID-19 patients. J Med Virol. 2020 Feb 27. [Epub ahead of print]. 